\title{
Study on biodegradation kinetics of di-2-ethylhexyl phthalate by newly isolated halotolerant Ochrobactrum anthropi strain L1-W
}

\author{
Jean Bosco Nshimiyimana ${ }^{1,2}$, Sujan Khadka ${ }^{1,3,4,7^{*}}$ (E), Piao Zou' ${ }^{1}$, Sanjib Adhikari ${ }^{3}$, Ram Proshad ${ }^{5,7}$, Alina Thapa ${ }^{6,7}$ \\ and Li Xiong ${ }^{1}$
}

\begin{abstract}
Objective: Di-2-ethylhexyl phthalate (DEHP) pollution is one of the major environmental concerns all over the world. This research aimed at studying the biodegradation kinetics of DEHP by a newly isolated bacterial strain. Water and sediment samples were collected from Wuhan South Lake and potent bacterial isolates were screened for DEHP degradation, characterized by biochemical, physiological, morphological and 165 rDNA gene sequencing, and optimized under suitable $\mathrm{pH}$, temperature, $\mathrm{NaCl}$ and DEHP concentrations. DEHP and its metabolites were quantified by High Performance Liquid Chromatography and their degradation kinetics were studied.

Results: The newly isolated bacterium was identified as Ochrobactrum anthropi strain L1-W with $99.63 \%$ similarity to Ochrobactrum anthropi ATCC 49188. It was capable of utilizing DEHP as the carbon source. The optimum growth temperature, $\mathrm{pH}, \mathrm{DEHP}$ and $\mathrm{NaCl}$ concentration for the strain $\mathrm{L} 1-\mathrm{W}$ were $30^{\circ} \mathrm{C}, 6,400 \mathrm{mg} / \mathrm{L}$ and $10 \mathrm{~g} / \mathrm{L}$ respectively. Strain L1-W was capable of degrading almost all (98.7\%) of DEHP when the initial concentration was $200 \mathrm{mg} / \mathrm{L}$ within a period of $72 \mathrm{~h}$. Besides, it was also found capable of degrading five other phthalates, thus making it a possible candidate for bioremediation of phthalates in the environmental settings.
\end{abstract}

Keywords: DEHP, Phthalates, Pollution, Ochrobactrum anthropi strain L1-W, Bioremediation

\section{Introduction}

Phthalates, also called as phthalate esters (PAEs), are chemical compounds belonging to the family of esters of phthalic acids. They are commonly used as plasticizers in polyvinyl chloride (PVC) and other polymers to enhance the durability as well as the elasticity [1]. Phthalates are the major components of wall coverings, food packagings, curtains, pesticides, rainwear, medical tubings, shoes and blood storage bags [2]. PAEs are less chemically bound in these products; consequently, they

\footnotetext{
*Correspondence: sukha11@yahoo.com

${ }^{1}$ Department of Biochemistry and Molecular Biology, School of Life

Sciences, Central China Normal University, Wuhan 430079, China

Full list of author information is available at the end of the article
}

are likely to leach into the environment and contaminate water, air, soil or sediments [3].

PAEs are regarded as endocrine-disrupting chemicals (EDCs) [4], and are known to alter sexual differentiation [5]. DEHP is the most commonly used phthalate, and it has been classified among hazardous chemicals by the China National Environmental Monitoring Center, the European Community and the United States Environmental Protection Agency [6]. DEHP and its major intermediate end products-MEHP (mono(2-ethylhexyl) phthalate) and PA (phthalic acid)-have been found to impair with the respiratory and nervous immune system as well as development in humans [7].

Both hydrolysis and photolysis have been found to be ineffective to remove DEHP from the contaminated environment $[8,9]$, leaving biological degradation as the 
sole effective and reliable option to remove DEHP from both terrestrial and aquatic contaminated environments and restoring their natural conditions [10]. Microbial degradation has more advantages over hydrolysis and photolysis because it is cost-effective, faster and environment-friendly [11].

Previous studies have reported different microorganisms such as Achromobacter denitrificans [12], Pseudomonas fluorescens [13], Bacillus megaterium YJB3 [14], Gordonia alkanivorans YC-RL2 [15], Mycobacterium sp. NK0301 [16], Providencia sp. 2D [9] capable of degrading DEHP and its metabolites. In China, most of the DEHP degraders have been isolated from rivers, lakes, sediments, activated sludge, plastic recycling plants, compost amended soil and wetland $[17,18]$. Only a few studies have documented successful biodegradation of DEHP with the use of microbes, although there are a lot of data available on the biodegradation of phthalates. In this context, a new and efficient bacterial strain was isolated, screened, characterized and optimized to study the biodegradation kinetics of DEHP.

\section{Main text}

\section{Study design and setting}

The work was conducted for 5 months from January to June 2019. The water and sediment samples were collected from Wuhan South Lake (Nanhu) in sterile plastic bottles and bags respectively and immediately brought to the Biochemistry and Molecular Biology unit laboratory of Central China Normal University, Wuhan, China, and stored in the refrigerator at $4{ }^{\circ} \mathrm{C}$ for further analysis.

\section{Methodology}

Few days following the sample collection, $5 \mathrm{~g}$ of sediment and $5 \mathrm{~mL}$ of water samples were mixed and diluted with $45 \mathrm{~mL}$ distilled water ( $\mathrm{pH} 7$ ) in a small conical flask and left standing still on the bench overnight. Next, $5 \mathrm{~mL}$ of supernatant was inoculated into a $50 \mathrm{~mL}$ Luria-Bertani (LB) medium, thoroughly mixed with a magnetic stirrer and incubated in a rotary shaker adjusted at $28{ }^{\circ} \mathrm{C}$ and $180 \mathrm{rpm}$ overnight. The broth culture was again subcultivated in inorganic salt agar (ISA) embedded with $500 \mathrm{mg} / \mathrm{L}$ of DEHP and incubated for 5-7 days. Only the bigger colony of bacteria capable of growing on ISA containing $500 \mathrm{mg} / \mathrm{L}$ of DEHP was selected for further studies. The physiological, biochemical and morphological characterization of the isolate was performed according to the Bergey's Bacterial Identification Manual [19] and the Common Bacterial Identification Manual [20]. Extraction of bacterial genomic DNA was carried out by using the kit (Biospin Bacteria Genomic DNA Extraction kit). Later, PCR was performed using universal primers: forward primer 27F (5'-AGAGTTTGATCCTGGCTC
AG-3) and reverse primer 1492R (5'-ACGGCTACC TTGTTACGACT-3) and gel electrophoresis was used to confirm the presence of DNA. The $16 S \mathrm{rDNA}$ gene sequencing of the resulting products was done by Nanjing Bioheng Biotech Co., Ltd. Phylogenetic tree was constructed by using the neighbour-joining, maximumparsimony and maximum-likelihood methods within the MEGA 7 software [21], and bootstrap values were calculated from 1000 replications.

In order to determine the optimal conditions of the isolate to degrade DEHP, single-factor optimization experiments were conducted with the following values: $\mathrm{pH}$ (4-8), temperature $\left(15-45^{\circ} \mathrm{C}\right)$ and $\mathrm{NaCl}$ concentrations $(10-100 \mathrm{~g} / \mathrm{L})$. The growth of the isolate was evaluated by measuring $\mathrm{OD}_{600}$ (optical density at $600 \mathrm{~nm}$ ) using UV-VIS spectrophotometer (Hitachi Industrial Components \& Equipment, Singapore). The isolate was subjected to different concentrations of DEHP (maximum: 100-600 mg/L and minimum: 1-10 mg/L). After $72 \mathrm{~h}$ of incubation, the degradation ability was evaluated by measuring $\mathrm{OD}_{600}$. An uninoculated medium containing DEHP was used as a control in all the cases. The isolate was also tested for its ability to degrade wider ranges of PAEs. DEHP and its metabolites were analyzed in $12 \mathrm{~h}$ interval by using HPLC (Shimadzu Corporation, Kyoto, Japan) as previously described by Ren et al. [22]. The degradation kinetics were studied using first-order kinetics equation. The half-life of the DEHP with different initial concentrations was also measured.

\section{Results}

\section{Isolation and identification of DEHP degrading bacterium}

Morphological, biochemical and physiological characteristics of the isolate are mentioned in Additional file 1: Table S1. Phylogenetic tree revealed that the bacterium was 99.63\% similar to Ochrobactrum anthropi ATCC 49188 (Fig. 1). Based on physiological, morphological, biochemical and $16 \mathrm{~S}$ rDNA gene sequence analysis, the isolate was identified as Ochrobactrum anthropi strain L1-W with gene bank accession number MT093466.

\section{Effect of $\mathrm{pH}$ and temperature on the growth of strain $\mathrm{L} 1-\mathrm{W}$}

The $\mathrm{pH}$ dependence of strain $\mathrm{L} 1-\mathrm{W}$ with its growth was studied within the $\mathrm{pH}$ range of $4-8$. The growth rate sharply increased with increase in $\mathrm{pH}$ up to 6 . However, it started to decrease when the $\mathrm{pH}$ was beyond 6, suggesting that the optimum growth $\mathrm{pH}$ for the strain L1-W is 6 (Additional file 1: Figure S1). Similarly, the optimal temperature for biodegradation of DEHP was found to be $30{ }^{\circ} \mathrm{C}$ above which the growth rate declined along with the increase in temperature (Additional file 1: Figure S2). 


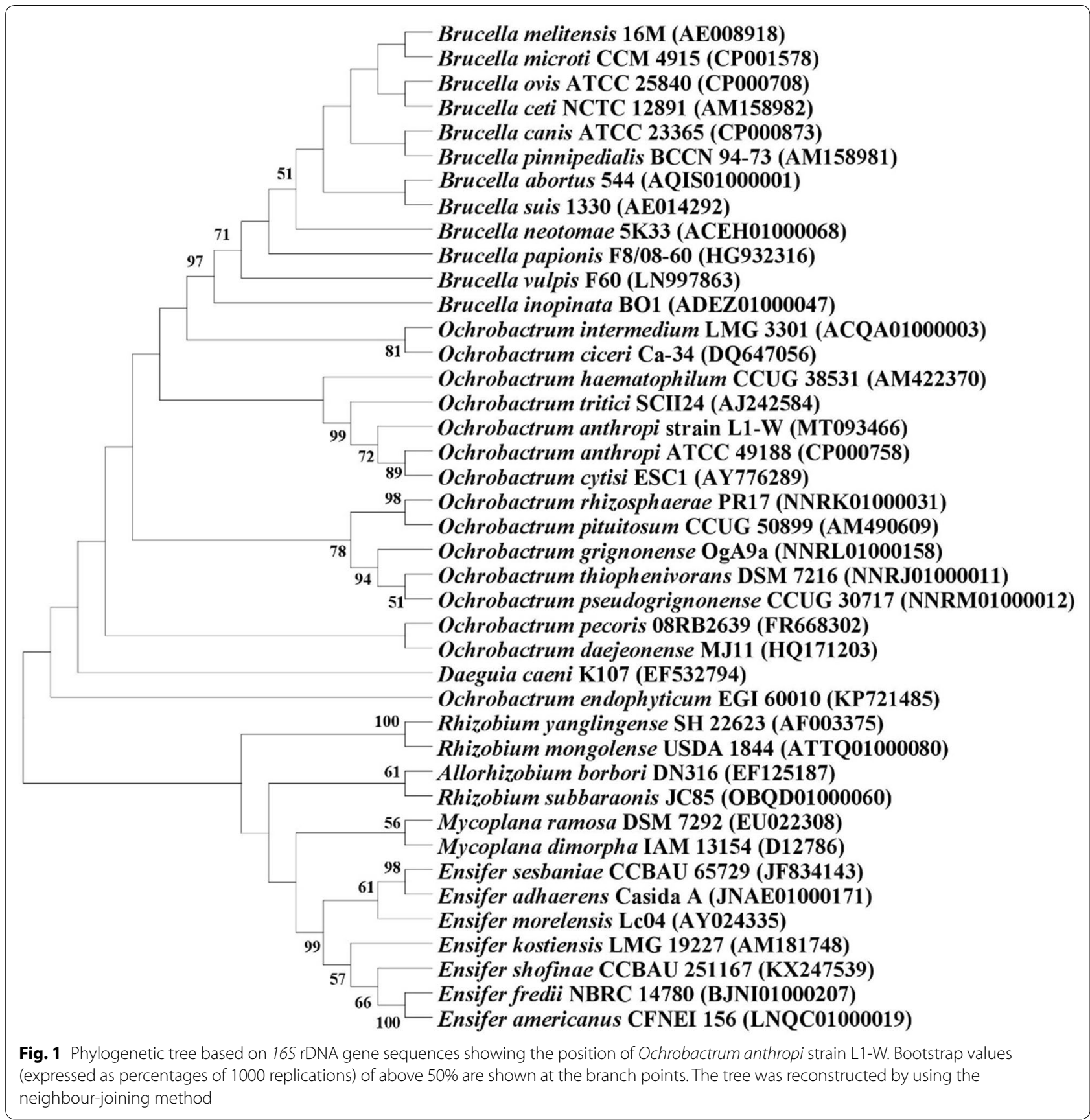

Effect of DEHP and $\mathrm{NaCl}$ concentration on the growth of strain L1-W

Strain L1-W exhibited the highest growth rate when the DEHP concentration was $400 \mathrm{mg} / \mathrm{L}$ but decreased thereafter (Additional file 1: Figure S3). Likewise, strain L1-W withstood the salinity up to $100 \mathrm{~g} / \mathrm{L}$ of $\mathrm{NaCl}$ exhibiting its halotolerant nature (Additional file 1: Figure S4).
Broad-spectrum substrate utilization

It was found that the strain L1-W can degrade at least six different PAEs; which makes it a plausible candidate for remediation of highly polluted environments (Additional file 1: Table S1). 
Table 1 Degradation kinetics of DEHP

\begin{tabular}{llc}
\hline $\begin{array}{l}\text { Initial } \\
\text { concentration } \\
\text { (mg/L) }\end{array}$ & Kinetic equation & Half-life (h) \\
\hline 100 & $\ln C=-0.08995 t+3.57816$ & 6.91 \\
200 & $\ln C=-0.06119 t+4.21163$ & 10.21 \\
300 & $\ln C=-0.05845 t+4.62491$ & 11.26 \\
400 & $\ln C=-0.04112 t+5.13567$ & 15.33 \\
500 & $\ln C=-0.03826 t+5.32104$ & 17.12 \\
\hline
\end{tabular}

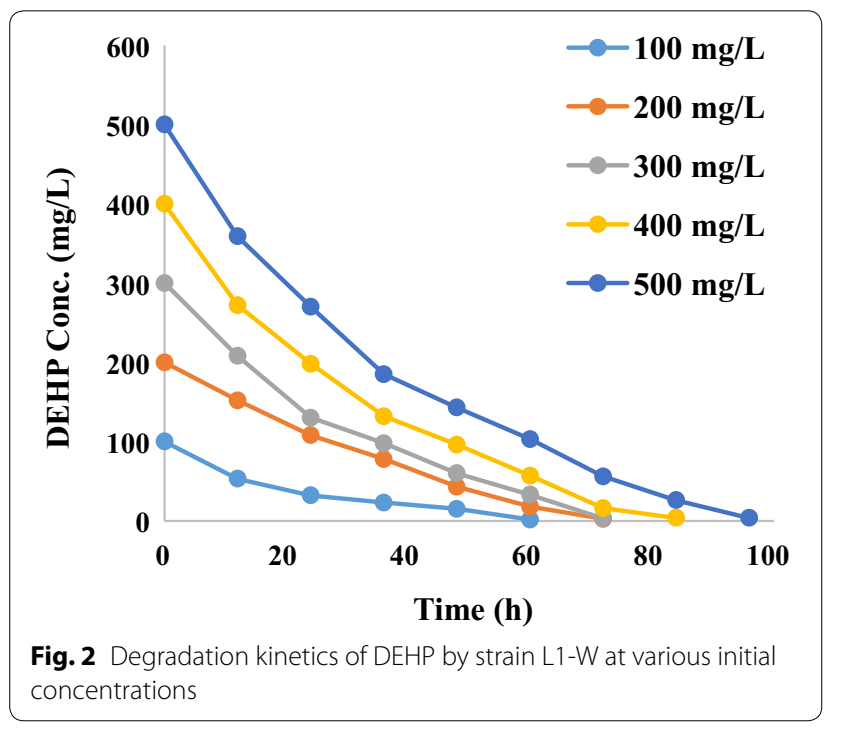

\section{Biodegradation kinetics of DEHP}

Degradation kinetics of DEHP was assumed to follow the first-order reaction with respect to the following equation:

$$
\ln C=-K t+A
$$

where $C, K, t$ and $A$ represent the concentration of DEHP, the first-order rate constant, time and a constant value respectively. The half-life of degradation of DEHP can be calculated by the formula: $t_{1 / 2}=\ln 2 / K$ where $t_{1 / 2}$ represents half-life.

Table 1 indicates kinetic equations of degradation of DEHP at various initial concentrations. It was found that 98.7\% of DEHP was degraded in $72 \mathrm{~h}$ when the initial concentration was $200 \mathrm{mg} / \mathrm{L}$ with the half-life of $10.21 \mathrm{~h}$ (Fig. 2).

\section{Discussion}

Wu et al. [23] reported the biodegradation of DBP by Ochrobactrum sp. which are regarded as one of the most effective microorganisms to survive the environments polluted by plasticizers because their cell wall and membrane are highly adapted to the harsh environment. High salinity content can affect the metabolic processes of the living organisms; therefore, reducing the ability to degrade DEHP [24]. Despite this, in the current study, strain L1-W showed a high salinity tolerance up to $100 \mathrm{~g} / \mathrm{L}$ which suggests that it may reduce the cost of desalinization in solid and wastewater treatment. Many halotolerant phthalates degraders have been isolated from marine environments [25, 26]. Yang et al. [25] isolated strain Rhodococcus ruber YC-YT1 from saline water which could tolerate up to $120 \mathrm{~g} / \mathrm{L}$ of $\mathrm{NaCl}$. A study conducted by Jin et al. [27] has identified halotolerant isolate-Sphingobium sp.-which degraded DBP at the salinity ranging from 0 to $4 \%$.

Studies have revealed that DEHP biodegradation is a temperature and $\mathrm{pH}$-dependent process [10]. This is because biodegradation is usually carried out by multiple enzymes which work under specific $\mathrm{pH}$ and temperature [15]. A certain microorganism will be regarded as effective if it has the ability to degrade pollutants in a wide range of temperature and $\mathrm{pH}$ values. For the most DEHP-degraders, for example, Acinetobacter sp. LMB-5 [28], Rhodococcus WJ4 [29] and Arthrobacter sp. C21 [30], maximum degradation occurred at $\mathrm{pH}$ 7; however, they were unable to carry on degradation at higher or lower $\mathrm{pH}$. On the other hand, some other microorganisms such as Rhodococcus sp. HS-D2 [31], Gordonia alkanivorans YC-RL2 [15], Acinetobacter sp. SN13 [11] and Pseudomonas fluorescens FS1 [13] have shown a wide $\mathrm{pH}$ range at 5-10, 6-11, 3-9, and 4-9 respectively. Compared with other degraders reported in various studies, the strain L1-W was capable of degrading DEHP in a wide $\mathrm{pH}$ range (4-8) and temperatures $\left(15-45{ }^{\circ} \mathrm{C}\right)$, with the optimum degradation occurring at pH 6 and temperature $30{ }^{\circ} \mathrm{C}$ respectively. This is almost similar to the findings of Xiao-Hua et al. [32] who reported a similar optimum $\mathrm{pH}$ and temperature for the degradation of dichlorvos by Ochrobactrum sp., but unlike the current study, there was almost no activity of the degraders when the $\mathrm{pH}$ was less than 5 .

It has been documented that more than one phthalate can exist simultaneously with other contaminants such as polychlorinated biphenyls (PCBs) in the same environment [33]. Several microorganisms have been reported capable of removing many PAEs from the environment. Wu et al. [23] have reported Ochrobactrum sp. capable of metabolizing three kinds of PAEs (DMP, DEP and DBP). It is worthy to note that not all bacteria have the ability to metabolize wider ranges of PAEs. For example, the research conducted by Sarkar et al. [34] concluded that Gordonia sp. Dop5 could not use PA. Compared with the above degraders, strain L1-W was found to be able to use at least six PAEs as its sole source of carbon, hence making it one of the 
excellent DEHP degraders with a wide range of substrate utilization ability.

Removing DEHP from its contaminated environment at low concentration raises some difficulties because if the concentration of the contaminant is very low it will hinder both growth and gene expression of the bacteria $[10,22]$. On the other hand, a higher concentration of DEHP also inhibits the growth of bacteria [35]. In the current study, strain L1-W remained viable and active at the lowest and highest concentration of DEHP at $0.5 \mathrm{mg} / \mathrm{L}$ and $600 \mathrm{mg} / \mathrm{L}$ respectively. A study conducted by Yang et al. [25] reported that a strain Rhodococcus ruber YC-YT1 could survive and remain active at $0.5 \mathrm{mg} / \mathrm{L}$ and $1000 \mathrm{mg} / \mathrm{L}$ concentrations of DEHP. Nahurira et. al. [15] revealed that Gordonia alkanivorans strain YC-RL2 could not continue to degrade DEHP when the concentration was above $1000 \mathrm{mg} / \mathrm{L}$. Acinetobacter sp. SN13 isolated by Xu et al. [11] showed the highest degradation of DEHP when the initial concentration of DEHP was $400 \mathrm{mg} / \mathrm{L}$ and it stopped when the concentration was above its optimum (500-1000 mg/L).

In the current study, degradation kinetics have revealed that the strain L1-W could degrade $98.7 \%$ of DEHP within $72 \mathrm{~h}$ when the initial concentration was $200 \mathrm{mg} / \mathrm{L}$. Yang et al. [25] isolated Rhodococcus rubber strain YC-YT1 that could degrade $60 \%$ of DEHP after 3 days given that the initial concentration was $0.5 \mathrm{mg} / \mathrm{L}$. Xu et al. [11] isolated Acinetobacter sp. SN13 and Nahurira et. al. [15] isolated Gordonia alkanivorans strain YC-RL2 capable of removing more than $90 \%$ of DEHP within 5 and 7 days respectively. This showed that strain L1-W can degrade DEHP more efficiently compared to the other bacteria previously studied.

\section{Conclusions}

Ochrobactrum anthropi strain L1-W, a newly isolated bacterial strain from the heavily polluted South Lake was characterized by physiological, morphological, biochemical and molecular techniques. Degradation of DEHP by the strain L1-W varied depending on the wide ranges of $\mathrm{pH}$ and temperature, and also with various concentrations of DEHP and $\mathrm{NaCl}$. The broad substrate utilization tests revealed that other PAEs such as BBP, DMP, DEP, DBP and DBEP could also be easily degraded by the strain L1-W. Such capabilities make it a promising candidate for bioremediation process in the PAEs contaminated sites.

\section{Limitations}

The study was unable to determine the formation of different intermediates and their routes under enzymatic actions exhibited by the strain L1-W. Several genes responsible for the biodegradation of DEHP were not studied.

\section{Supplementary information}

Supplementary information accompanies this paper at https://doi. org/10.1186/s13104-020-05096-0.

Additional file 1. Additional figures and table.

\section{Abbreviations}

DEHP: Di-2-ethylhexyl phthalate; PAEs: Phthalate esters; PVC: Polyvinyl chloride; EDCs: Endocrine-disrupting chemicals; DMP: Di-methyl phthalate; DEP: Di-ethyl phthalate; DBP: Di-butyl phthalate; DBEP: Dibutoxy ethyl phthalate; DBP: Dibutyl phthalate; LB: Luria-Bertani; MEHP: Mono(2-ethylhexyl) phthalate; PA: Phthalic acid; PCBs: Polychlorinated biphenyls.

\section{Acknowledgements}

We are indebted to the staff of Biochemistry and Molecular Biology Unit, School of Life Sciences, Central China Normal University for their invaluable support to conduct this research work.

\section{Authors' contributions}

LX conceived the concept and design of this study. SK, JBN and PZ performed experimental work. SK, JBN, SA, RP and AT analyzed the data and prepared the final draft of the manuscript. All authors read and approved the final manuscript

Funding

No specific funding was received for this study.

\section{Availability of data and materials}

All datasets generated or analyzed during this study are included in the manuscript.

\section{Ethics approval and consent to participate}

Ethical approval to carry out this research was obtained from the Department of Biochemistry and Molecular Biology, School of Life Sciences, Central China Normal University, Wuhan, Hubei, China. This article does not contain any studies with human participants or animals.

Consent of publication

Not applicable.

\section{Competing interests}

The authors declare that they have no competing interests.

\section{Author details}

${ }^{1}$ Department of Biochemistry and Molecular Biology, School of Life Sciences, Central China Normal University, Wuhan 430079, China. ${ }^{2}$ Department of Natural Resources and Environment Management, Protestant Institute of Arts and Social Science, Po Box 619, Huye, Rwanda. ${ }^{3}$ Department of Microbiology, Birendra Multiple Campus, Tribhuvan University, Bharatpur, Chitwan 44200, Nepal. ${ }^{4}$ State Key Laboratory of Environmental Aquatic Chemistry, Research Center for Eco-Environmental Sciences, Chinese Academy of Sciences, Beijing 100085, China. ${ }^{5}$ Key Laboratory of Mountain Surface Process and Ecological Regulation, Institute of Mountain Hazards and Environment, Chinese Academy of Sciences, Chengdu 610041, China. ${ }^{6}$ State Key Laboratory of Alpine Ecology and Biodiversity, Institute of Tibetan Plateau Research, Chinese Academy of Sciences, Beijing 100101, China. ${ }^{7}$ University of Chinese Academy of Sciences, Beijing 100049, China.

Received: 12 March 2020 Accepted: 18 May 2020

Published online: 24 May 2020 


\section{References}

1. Ahuactzin-Pérez M, Tlecuitl-Beristain S, García-Dávila J, Santacruz-Juárez E, González-Pérez M, Gutiérrez-Ruíz MC, et al. A novel biodegradation pathway of the endocrine-disruptor di(2-ethyl hexyl) phthalate by Pleurotus ostreatus based on quantum chemical investigation. Ecotoxicol Environ Saf. 2018;147:494-9.

2. He L, Fan S, Müller K, Wang H, Che L, Xu S, et al. Comparative analysis biochar and compost-induced degradation of di-(2-ethylhexyl) phthalate in soils. Sci Total Environ. 2018:625:987-93.

3. Xia X, Yang L, Bu Q, Liu R. Levels, distribution, and health risk of phthalate esters in urban soils of Beijing, China. J Environ Qual. 2011;40:1643-51.

4. Wang C, Yang L, Wang S, Zhang Z, Yu Y, Wang M, et al. The classic EDCS, phthalate esters and organochlorines, in relation to abnormal sperm quality: a systematic review with meta-analysis. Sci Rep. 2016:6:19982.

5. Andrade AJ, Grande SW, Talsness CE, Grote K, Golombiewski A, et al. A dose-response study following in utero and lactational exposure to di-(2-ethylhexyl) phthalate (DEHP): effects on androgenic status, developmental landmarks and testicular histology in male offspring rats. Toxicology. 2006;225(1):64-74.

6. Dargnat C, Teil M, Chevreuil M, Blanchard M. Phthalate removal throughout wastewater treatment plant. Sci Total Environ. 2009;407(4):1235-44.

7. Li B, Xu X, Zhu Y, Cao J, Zhang Y, Huo X. Neonatal phthalate ester exposure induced placental MTs, FATP1 and HFABP mRNA expression in two districts of southeast China. Sci Rep. 2016;6:21004.

8. Benjamin S, Pradeep S, Josh MS, Kumar S, Masai E. A monograph on the remediation of hazardous phthalates. J Hazard Mater 2015;298:58-72.

9. Zhao HM, Du H, Feng NX, Xiang L, Li YW, Li H, Cai QY, Mo CH. Biodegradation of di-n-butylphthalate and phthalic acid by a novel Providencia sp. $2 \mathrm{D}$ and its stimulation in a compost-amended soil. Biol Fertil Soils. 2016:52:65-76.

10. Ren L, Lin Z, Liu H, Hu H. Bacteria-mediated phthalic acid esters degradation and related molecular mechanisms. Appl Microbiol Biotechnol. 2018;102(3):1085-96.

11. Xu J, Lu Q, de Toledo RA, Shim H. Degradation of di-2-ethylhexyl phthalate (DEHP) by an indigenous isolate Acinetobacter sp. SN13. Int Biodeterior Biodegrad. 2017;117:205-14.

12. Pradeep S, Josh MS, Binod P, Devi RS, Balachandran S, Anderson RC, et al. Achromobacter denitrificans strain SP1 efficiently remediates di(2-ethylhexyl) phthalate. Ecotoxicol Environ Saf. 2005;112:114-21.

13. Zeng F, Cui K, Li X, Fu J, Sheng G. Biodegradation kinetics of phthalate esters by Pseudomonas fluoresences FS1. Process Biochem. 2004:39(9):1125-9.

14. Feng N, Yu J, Mo C, Zhao H, Li Y, Wu B, et al. Biodegradation of di-n-butyl phthalate (DBP) by a novel endophytic Bacillus megaterium strain YJB3. Sci Total Environ. 2018;616-617:117-27.

15. Nahurira R, Ren L, Song J, Jia Y, Wang J, Fan S, et al. Degradation of di(2ethylhexyl) phthalate by a novel Gordonia alkanivorans strain YC-RL2. Curr Microbiol. 2017;74:309-19.

16. Nakamiya $\mathrm{K}$, Hashimoto $\mathrm{S}$, Ito $\mathrm{H}$, Edmonds JS, Yasuhara A, Morita M. Microbial treatment of bis(2-ethylhexyl) phthalate in polyvinyl chloride with isolated bacteria. J Biosci Bioeng. 2005;99(2):115-9.

17. He Z, Xiao H, Tang L, Min H, Lu Z. Biodegradation of di- $n$-butyl phthalate by a stable bacterial consortium, HD-1, enriched from activated sludge. Bioresour Technol. 2013;128:526-32.

18. Wang J, Bo L, Li L, Wang D, Chen G, Christie P, et al. Occurrence of phthalate esters in river sediments in areas with different land use patterns. Sc Total Environ. 2014;500:113-9.

19. Krieg NR, Holt JC. Bergey's manual of systematic bacteriology. 1st ed. Baltimore: Williams and Wilkins; 1984.
20. Miaoying C. East show strains, Cai Miaoying common bacterial identification manual system. Beijing: Science Press; 2001

21. Kumar S, Stecher G, Tamura K. MEGA 7: molecular evolutionary genetics analysis version 7.0 for bigger datasets. Mol Biol Evol. 2016;33:1870-4.

22. Ren L, Jia Y, Ruth N, Shi Y, Wang J, Qiao C, et al. Biotransformations of bisphenols mediated by a novel Arthrobacter sp. strain YC-RL1. Appl Microbiol Biotechnol. 2016;100(4):1967-76.

23. Wu XL, Wang YY, Liang RX, Dai QY, Chao WL. Degradation of di-n-butyl phthalate by newly isolated Ochrobactrum sp. Bull Environ Contam Toxicol. 2010;85(3):235-7.

24. Cortés-Lorenzo C, Rodríguez-Díaz M, López-Lopez C, Sánchez-Peinado M, Rodelas B, González-López J. Effect of salinity on enzymatic activities in a submerged fixed bed biofilm reactor for municipal sewage treatment. Bioresour Technol. 2012:121:312-9.

25. Yang T, Ren L, Jia Y, Fan S, Wang J, Wang J, et al. Biodegradation of di(2-ethylhexyl) phthalate by Rhodococcus ruber YC-YT1 in contaminated water and soil. Int J Environ Res Public Health. 2018;15:964.

26. Wang Y, Yin B, Hong Y, Gu JD. Degradation of dimethyl carboxylic phthalate ester by Burkholderia cepacia DA2 isolated from marine sediment of South China Sea. Ecotoxicology. 2008;17(8):845-52.

27. Jin D, Kong X, Cui B, Bai Z, Zhang H. Biodegradation of di-n-butyl phthalate by a newly isolated halotolerant Sphingobium sp. Int J Mol Sci. 2013;14(12):24046-54.

28. Fang $Y$, Zhang L, Wang J, Zhou Y, Ye B. Biodegradation of phthalate esters by a newly isolated Acinetobacter sp. strain LMB-5 and characteristics of its esterase. Pedosphere. 2017;27(3):606-15.

29. Wang J, Zhang M, Chen T, Zhu Y, Teng Y, Luo Y, et al. Isolation and identification of a di-(2-ethylhexyl) phthalate-degrading bacterium and its role in the bioremediation of a contaminated soil. Pedosphere. 2015;25(2):202-11.

30. Wen Z, Gao D, Wu W. Biodegradation and kinetic analysis of phthalates by an Arthrobacter strain isolated from constructed wetland soil. Appl Microbiol Biotechnol. 2014;98(10):4683-90.

31. Zhang Y, Chen H, Liu J, Geng G, Liu D, Geng H, et al. Genome sequencing and biodegradation characteristics of the $n$-butyl benzyl phthalate degrading bacterium-Rhodococcus sp. HS-D2. Int Biodeterior Biodegrad. 2016;128:56-62.

32. Xiao-Hua Z, Guo-Shun Z, Zhong-Hui Z, Jian-Hong X, Shun-Peng L. Isolation and characterization of a dichlorvos-degrading strain DDV-1 of Ochrobactrum sp. Pedosphere. 2006;16(1):64-71.

33. Fiandanese N, Borromeo V, Berrini A, Fischer B, Schaedlich K, Schmidt J. Secchi C, Pocar P. Maternal exposure to a mixture of di(2-ethylhexyl) phthalate (DEHP) and polychlorinated biphenyls (PCBs) causes reproductive dysfunction in adult male mouse offspring. Reprod Toxicol. 2016;65:123-32.

34. Sarkar J, Chowdhury PP, Dutta TK. Complete degradation of din-octyl phthalate by Gordonia sp. strain Dop5. Chemosphere. 2013;90(10):2571-7.

35. Brundrett J, Orach J, Sonderegger L, Yan T. Investigating the effects of bis(2-ethylhexyl) phthalate (DEHP) on the growth of Escherichia coli strain BL21. J Exp Microbiol Immunol. 2018:22:1-9.

\section{Publisher's Note}

Springer Nature remains neutral with regard to jurisdictional claims in published maps and institutional affiliations. 